\title{
Heterotopic ossification in combat amputees from Afghanistan and Iraq wars: Five case histories and results from a small series of patients
}

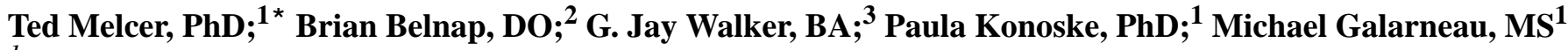 \\ ${ }^{1}$ Medical Modeling, Simulation and Mission Support Department, Naval Health Research Center, San Diego, CA; \\ ${ }^{2}$ Comprehensive Complex and Casualty Care Center, Naval Medical Center San Diego, San Diego, CA; ${ }^{3}$ Science \\ Applications International Corporation, McLean, VA
}

\begin{abstract}
Heterotopic ossification (HO) is excess bone growth in soft tissues that frequently occurs in the residual limbs of combat amputees injured in Operation Iraqi Freedom and Operation Enduring Freedom, or Iraq and Afghanistan wars, respectively. $\mathrm{HO}$ can interfere with prosthetic use and walking and delay patient rehabilitation. This article describes symptomatic and/or radiographic evidence of $\mathrm{HO}$ in a patient series of combat amputees rehabilitating at a military amputee care clinic (27 patients/33 limbs). We conducted a retrospective review of patient records and physician interviews to document evidence of HO symptoms in these limbs (e.g., pain during prosthetic use, skin breakdown). Results showed HO-related symptoms in 10 of the 33 residual limbs. Radiographs were available for 25 of the 33 limbs, and a physician identified at least moderate HO in 15 of the radiographs. However, 5 of the 15 patients who showed at least moderate radiographic HO did not report adverse symptoms. Five individual patient histories described HO onset, symptoms, treatments, and outcomes. These case histories illustrated how HO location relative to pressure-sensitive/pressuretolerant areas of the residual limb may determine whether patients experienced symptoms. These histories revealed the uncommon but novel finding of potential benefits of $\mathrm{HO}$ for prosthetic suspension.
\end{abstract}

Key words: Afghanistan war, amputation, blast injury, combat amputee, heterotopic ossification, Iraq war, physical medicine, prosthesis, radiograph, rehabilitation.

\section{INTRODUCTION}

Heterotopic ossification (HO) is a significant postinjury complication that impairs the rehabilitation of U.S. combat amputees injured in Operation Iraqi Freedom and Operation Enduring Freedom, or Iraq and Afghanistan wars, respectively, and represents one of the major challenges facing military orthopedic surgeons [1-5]. HO refers to excess bone growth in soft tissues that can be seen developing in radiographs of residual limbs weeks after traumatic injury. In many cases, HO can cause symptoms such as skin breakdown and pain during prosthetic use and interfere with the patient's ability to walk. Most of these symptomatic patients can have their pain resolved through conservative treatments such as prosthetic adjustments to restore a comfortable fit. A minority of combat amputees eventually require surgical excision of the ectopic bone to relieve their HO symptoms [1-2]. Interestingly, some other patients show evidence of $\mathrm{HO}$ in radiographs without any apparent symptoms and therefore

\footnotetext{
Abbreviations: $\mathrm{HO}=$ heterotopic ossification, IED = improvised explosive device, $\mathrm{TBI}=$ traumatic brain injury.

* Address all correspondence to Ted Melcer, PhD; Medical Modeling, Simulation and Mission Support Department, Naval Health Research Center, 140 Sylvester Rd, San Diego, CA 92106; 619-553-8404, fax: 619-553-8378.

Email: ted.melcer@med.navy.mil

DOI:10.1682/JRRD.2010.03.0033
} 
require no treatment. Unfortunately, little research has integrated radiographic and symptomatic evidence of $\mathrm{HO}$ to explain variability in symptoms among recent combat amputee patients.

A study of available patient radiographs indicated at least mild HO in 36 to 63 percent of recent U.S. combat amputees [1]. The remaining patients did not show evidence of $\mathrm{HO}$ in their radiographs. Amputations performed within the zone of blast injury [1] and those with higher injury severity scores [3] had increased risk of developing HO. Previous studies used large samples of patient radiographs but did not systematically record which patients had adverse symptoms associated with the HO seen in their radiographs [1,3].

Descriptions of $\mathrm{HO}$ in individual combat-amputee patients are sparse in detailing their specific injuries, radiographs, treatments, symptoms, and outcomes, including return to duty. One recent review included a general approach to evaluation and treatment and included radiographs illustrating mild, moderate, and severe $\mathrm{HO}$ [2]. The authors recommended that physicians should determine HO severity using physical examinations, patient symptoms, and/or review of radiographs. Treatment should begin with nonsurgical approaches such as a period of rest followed by rehabilitation and prosthetic modifications. Surgical excision may follow if symptoms persist, usually in a minority of cases [1-2]. A few brief articles described $\mathrm{HO}$ in civilians following traumatic amputations [6-8], but only one involved blast injuries [6].

Individual case histories may illustrate the mechanisms by which HO interferes with prosthetic use and causes symptoms in some patients but not others. These descriptions are important, given the unique injury profiles of recent combat amputees [9-12] and the high frequency of $\mathrm{HO}$ occurring in this population $[1,2,13]$. Patient histories can be instructive for both civilian and military prosthetists, surgeons, and physical rehabilitation specialists.

The present article describes $\mathrm{HO}$ in a patient series of 27 recent U.S. combat amputees treated at one military rehabilitation center between 2007 and 2008. The objectives were to (1) summarize symptomatic and radiographic evidence of excess bone growth and (2) describe selected case histories of patients to illustrate the range of patient variability in radiographic and/or symptomatic evidence of $\mathrm{HO}$ and their specific treatments and outcomes.

\section{METHODS}

\section{Subjects}

Subjects were 27 U.S. combat amputees who were participating in rehabilitation at the same military amputee care center. The patients had major limb amputations (excluding fingers and toes) following injury during the Afghanistan and Iraq wars.

\section{Inclusions and Exclusions}

No patients in the case series had paralysis or brain injury that prevented them from walking. The study began with 28 patients, but 1 patient was excluded because of missing data due to early transfer from the rehabilitation program, resulting in the sample size of 27 patients.

\section{Patient Series}

The study sample consisted of the 27 patients with 33 residual limbs. Twenty-five residual limbs followed amputations within 30 days of injury. The remaining eight residual limbs followed elective amputations, which were delayed at least 6 months postinjury.

\section{Research Design}

This was a retrospective study of existing medical records for a series of patients treated at one military clinic between 2007 and 2008. For all patients, we extracted the following demographic and injury information from their medical records: age, sex, mechanism of injury, anatomic location of amputation, injury severity scores [14], and associated complications. We have routinely coded injuries and complications of recent combat-injured patients [15]. We did not record soft-tissue treatments (e.g., irrigations, duration of negative pressure-wound therapy) because two previous studies found little evidence supporting their role in the development of HO $[1,3]$. Patient symptoms were followed for at least 12 months postamputation because $\mathrm{HO}$ in combat amputees usually develops within this period.

\section{Symptoms, Radiographs, and Case Histories}

Symptoms and treatments that correlated with the site of $\mathrm{HO}$ included pain, prosthetic adjustments, and/or surgical excision. Radiographic analysis was based on the treating physician's review of radiographs (as available $>2$ months after amputation) ordered as part of each patient's specific care. Referencing previous radiographic images of mild, moderate, and severe HO [1], the physician judged whether the present radiographs (anteroposterior or 
lateral views) were most similar to the previous images of mild or to those of moderate to severe HO. Physicians reviewed all available radiographs for each patient to ensure particular radiographic views did not obscure excess bone growth. Categorization of radiographs as none to mild or moderate to severe was based on the view judged as showing the greatest area of HO.

Case histories were selected based on expert judgment of the treating physician, an approach that was informative in previous case descriptions of combat-limb injuries [12]. They were selected to illustrate the range of $\mathrm{HO}$ care issues encountered by the physician in recent years in military amputee clinics $[5,9]$, particularly those relevant for optimizing prosthetic use by lower-limb amputees. These issues included symptoms and location of excess bone growth relative to the prosthetic, prosthetic modifications, preventive medications, $\mathrm{HO}$ after delayed or elective amputation, possible benefits of $\mathrm{HO}$ for prosthetic fitting, and risks and/or benefits of surgical excision.

\section{RESULTS}

\section{Demographics and Injury Characteristics}

Table 1 shows that the patients were relatively young males who sustained explosive or blast injuries, resulting

Table 1.

Demographic and injury characteristics of patient case series $(n=27$ patients, 33 limbs).

\begin{tabular}{|c|c|c|c|c|}
\hline $\begin{array}{c}\text { Demographic/Injury } \\
\text { Characteristic }\end{array}$ & Mean & Median & Range & No. \\
\hline Age & 24.7 & 22.0 & 19-38 & - \\
\hline \multicolumn{5}{|l|}{ Sex } \\
\hline Male & - & - & - & 27 \\
\hline Female & - & - & - & 0 \\
\hline \multicolumn{5}{|l|}{ Mechanism of Injury } \\
\hline $\begin{array}{l}\text { Improvised Explosive } \\
\text { Device }\end{array}$ & - & - & - & 26 \\
\hline Crush Injury & - & - & - & 1 \\
\hline Injury Severity Score & 16.2 & 14.0 & 9-38 & - \\
\hline \multicolumn{5}{|l|}{$\begin{array}{l}\text { Anatomic Location of } \\
\text { Amputation }\end{array}$} \\
\hline Transfemoral & - & - & - & 14 \\
\hline Transtibial & - & - & - & 14 \\
\hline Transradial & - & - & - & 2 \\
\hline Wrist Disarticulation & - & - & - & 2 \\
\hline Transhumeral & - & - & - & 1 \\
\hline
\end{tabular}

in a moderate to serious injury severity [14]. Transtibial and transfemoral locations accounted for 28 of 33 amputations and the remaining 5 limbs lost were upper limbs.

\section{Symptomatic and Radiographic Evidence of $\mathrm{HO}$}

HO symptoms occurred in 10 of 33 residual limbs, and the ectopic bone in 4 of these limbs required surgical excision. Figure 1 shows that 25 limbs had radiographs available while 8 limbs did not have radiographs available for analysis. Table 2 shows the results for the 25 limbs that had radiographs available. Fifteen of twenty-five limbs showed substantial HO (more than mild). Of these 15 limbs, 10 showed radiographic and symptomatic $\mathrm{HO}$, while 5 of 15 showed radiographic $\mathrm{HO}$ without symptoms. The other 10 limbs showing no $\mathrm{HO}$ or mild radiographic $\mathrm{HO}$ had no symptoms. Finally, radiographic HO occurred in three of the eight patients following delayed amputations, which were performed after at least a 6-month trial of limb salvage.

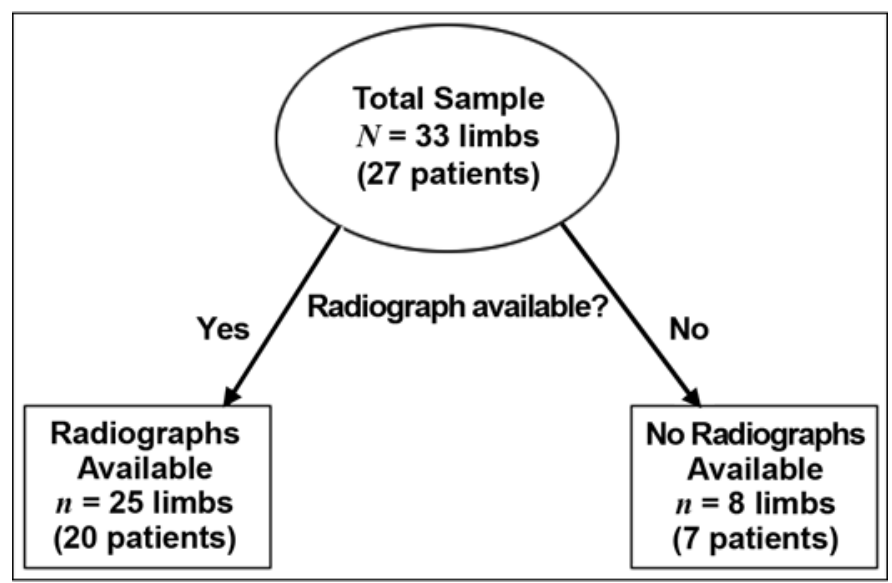

Figure 1.

Sample size of residual limbs and subsamples of limbs with or without radiographs available. Symptomatic evidence was available for all 33 limbs while only 25 limbs had radiographic evidence available.

Table 2.

Radiographic and symptomatic cases of heterotopic ossification (HO) among patients with available radiographs taken at least 2 months after amputation $\left(n=25\right.$ limbs $\left.^{*}\right)$.

\begin{tabular}{ccc}
\hline \multirow{2}{*}{ Symptoms } & \multicolumn{2}{c}{ HO in Radiograph } \\
\cline { 2 - 3 } & Yes & None or Mild \\
\hline Yes & $n=10$ & $n=0$ \\
No & $n=5$ & $n=10$ \\
*Eight limbs had no radiographs available and had no symptoms. \\
\hline
\end{tabular}




\section{Case Histories}

\section{Case 1}

Case history 1 illustrated moderate HO without apparent symptoms or adverse effects on patient use of a prosthesis. This patient had a right transfemoral amputation and a left transtibial amputation after being struck by an improvised explosive device (IED). He also had a large gluteal soft-tissue wound, and his medical team noted this wound was at risk for HO. The patient was diagnosed with a pulmonary embolism soon after return to a U.S. treatment facility and was treated with Coumadin therapy. A bone scan revealed a small amount of $\mathrm{HO}$ in the soft-tissue wound, and the patient was prescribed etidronate as preventive treatment for further HO. The patient was discharged from hospital care between 1 and 2 months postinjury and continued in the Amputee Patient Care Program. The patient was fitted with prostheses for both legs and progressed to walking within 3 months postinjury. HO developed in the right residual limb 5 months after combat injury (Figure 2) and was palpable during physical examination.

The patient also continued to show evidence of HO in the right gluteal soft-tissue wound. However, the patient reported no pain or prosthetic use issues related to the $\mathrm{HO}$ in the residual limb because the excess bone did not interfere with prosthetic fitting. This patient case was interesting because the radiograph showed moderate HO, which was also palpable, but it was asymptomatic. The patient required no follow-up adjustments or other treatments and returned to duty in a noncombat role.

\section{Case 2}

Case history 2 illustrates management of moderate $\mathrm{HO}$ in a transfemoral amputee including apparent benefits of excess bone growth for prosthetic fitting and use of preventive medication. This patient was struck by an IED, seriously injuring his left lower limb, which was followed by a left transfemoral amputation in theater. The patient had minor soft-tissue injuries to his right leg and left arm, and about 1 week postinjury was evacuated to a U.S. treatment facility, where surgeons performed final closure of the residual limb and initiated preventive HO medications (i.e., etidronate). His medical team believed the medications were appropriate because the patient had no other contraindications, such as healing fractures. One month postinjury, $\mathrm{HO}$ was palpable in the residual limb, but the patient did not report significant pain (Figure 3). The

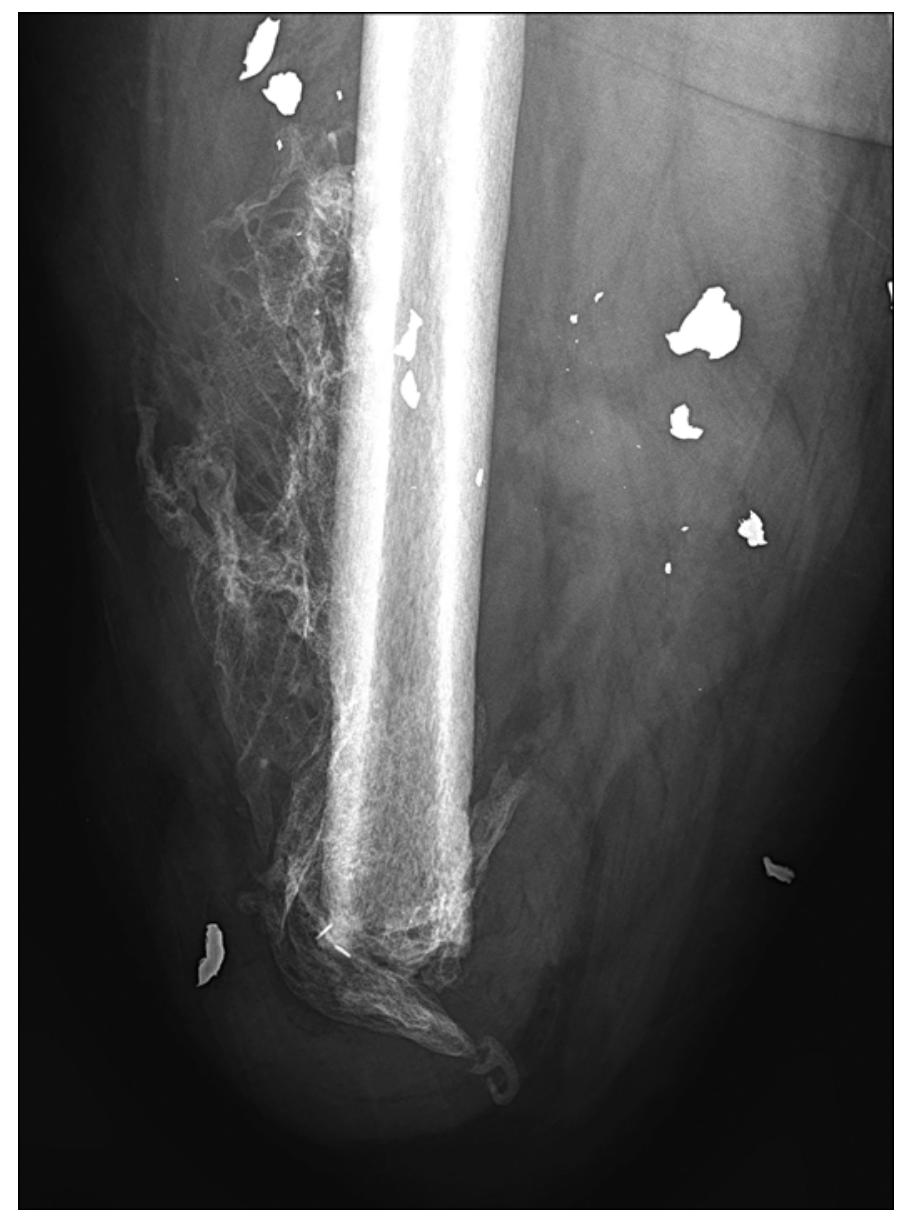

Figure 2.

Radiograph showing moderate amount of heterotopic ossification (HO), which was palpable, in transfemoral amputation for case history 1 . HO did not cause pain or other symptoms that interfered with prosthetic use, and patient returned to duty in noncombat role.

patient developed pain issues from the $\mathrm{HO}$ after 4 months of prosthetic use, and fitting adjustments reduced the pain. The patient continued to recover considerable function, including high-level sports activities using a prosthesis. The prosthetist noted that the ectopic bone had unintended benefits, namely providing an anatomic mechanism for suspension of the residual limb within the prosthetic socket [16]. The patient continued to use the prosthesis without significant issues, including during a 6-month tour of duty in the Afghanistan war in a noncombat role.

\section{Case 3}

Case history 3 illustrates occurrence of $\mathrm{HO}$ in a residual limb following a delayed elective amputation. This 
patient was struck by an IED, extensively injuring both lower and upper limbs and causing mild to moderate traumatic brain injury (TBI). He was evacuated to a U.S. medical facility and treated for 45 days. Both lower limbs had fractures near the ankles that required external fixation. The patient had a lumbar plexopathy that compromised function of the lower right leg and foot. An electromyogram showed poor chance of recovery of motor control or sensation below the right knee. The fractures in the right ankle did not heal properly; therefore, primary options were ankle fusion or transtibial amputation. To enhance functional outcome, the patient elected to have a right transtibial amputation 7 months after com-

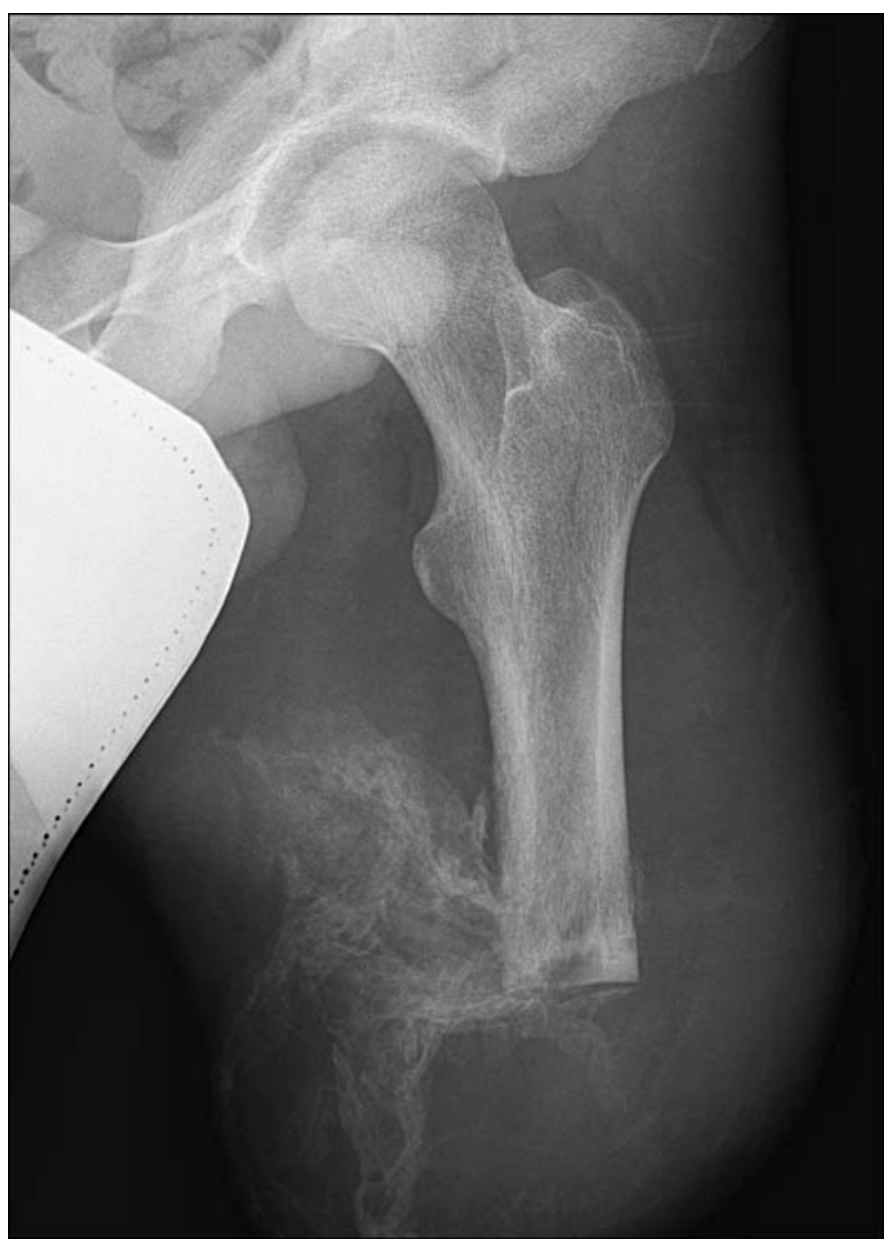

Figure 3.

Radiograph showing heterotopic ossification, which was palpable, in transfemoral amputation for case history 2. Patient had pain issues managed successfully with prosthetic adjustments and recovered to high level of functioning, returning to duty in Iraq (Operation Iraqi Freedom) in noncombat role. bat injury. A preamputation radiograph taken within a month of surgery and a radiograph taken 1 month postamputation were both clear of HO. Approximately 2 months after amputation, HO began to appear in the lower-right residual limb. The same location showed additional growth of the ectopic bone 6 months postamputation (Figure 4, the medial distal spur).

The specific location of the heterotopic bone affected a pressure-sensitive area of the residual limb relative to the prosthetic socket [16-17]. Interestingly, the location of this bone growth was not correlated with the site of the external

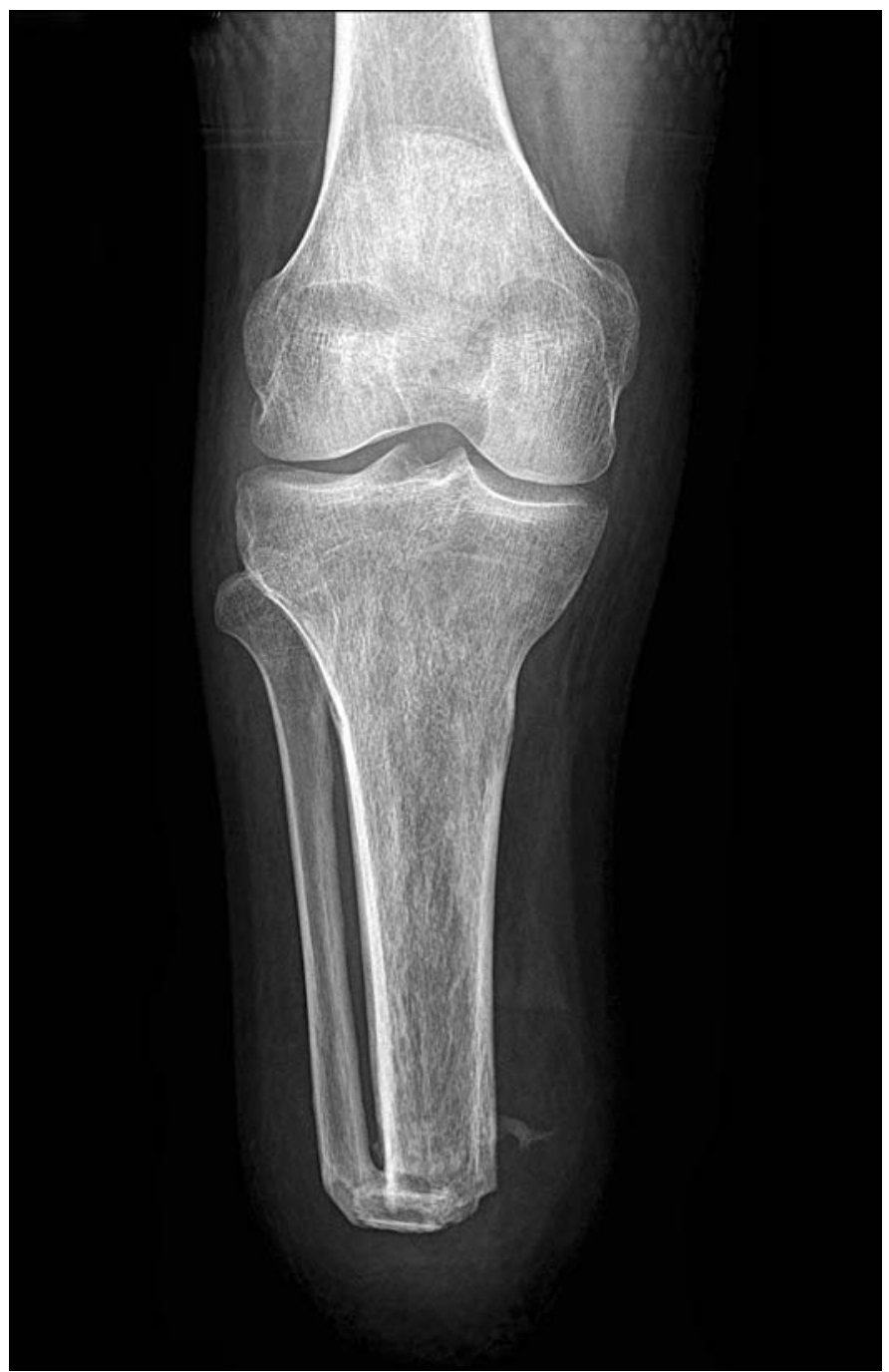

Figure 4.

Radiograph showing specific location of heterotopic ossification (HO), medial distal spur, following an elective transtibial amputation for case history 3. HO continued to cause limited pain during highlevel activities but did not interfere with most day-to-day functioning. 
fixation previously installed near the ankle. The $\mathrm{HO}$ in this lower limb did not interfere with most daily activities, but it did cause some pain following certain higher-level activities, such as deep squatting. Adjustments to the patient's prosthesis did not resolve the problem, but surgical excision successfully resolved symptoms.

This patient also had severe soft-tissue injuries to his nonamputated left arm that required a skin graft. Subsequent to surgery, the patient had loss of range of motion in the arm due to $\mathrm{HO}$, which effectively fused the patient's arm in an extended position, allowing only $5^{\circ}$ of flexion at the elbow. Surgeons excised much of the ectopic bone in the nonamputated arm, and subsequently, the patient improved range of motion in his left arm to $100^{\circ}$ flexion. This patient then improved functioning in various activities of daily living and driving a vehicle.

\section{Case 4}

Case history 4 illustrates the use of preventive medication and symptomatic HO following breakdown of a skin graft. This patient had bilateral transfemoral amputations and mild TBI associated with IED injuries. He received celecoxib (200 mg/d) and etidronate as prophylaxis for HO soon after his return to the United States. He was fitted with prostheses and successfully learned to walk. This patient had a split-thickness skin graft on his right residual limb, and radiological reports indicated HO development about 1 year postinjury (Figure 5). The HO eventually pushed through the skin graft, causing recurrent skin breakdown, and the patient developed cellulitis near the HO location. Six to nine months postinjury, the recurrent skin breakdown in the right residual limb interfered with prosthetic use. The patient was motivated to avoid surgical excision because of recovery from multiple other procedures and attempted several nonsurgical solutions, such as prosthetic adjustments. However, these adjustments were unsuccessful and, because of the recurrent skin breakdown, the patient had to stop walking. This patient was discharged from military service. His patient chart indicated surgical excision was scheduled in the near future.

\section{Case 5}

Case history 5 illustrates the effects of a focused protrusion of $\mathrm{HO}$ following and an elective amputation 8 months after being struck by an IED. This patient had multiple injuries, including bilateral foot fractures, a fractured right arm, and a concussion, and returned to U.S.

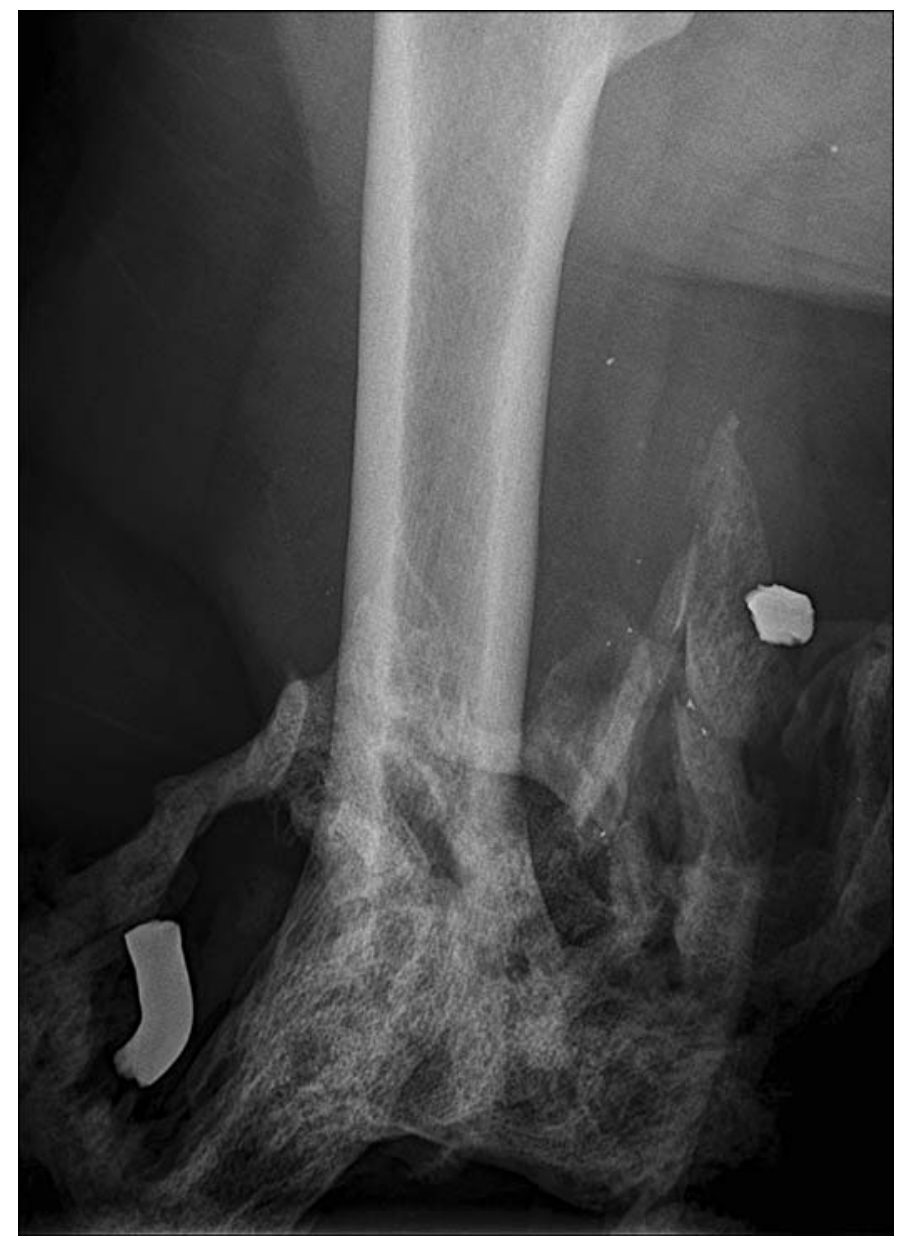

Figure 5.

Radiograph showing heterotopic ossification (HO) in transfemoral amputation for case history 4 . HO caused recurrent skin breakdown through split-thickness skin graft that interfered with prosthetic use. Fitting adjustments were unsuccessful, and surgical excision was scheduled.

medical facilities without a limb amputation following initial reconstruction procedures. An elective transtibial amputation was performed because of poor function and pain in the left leg. The patient's preamputation radiograph, taken within 1 month before surgery, was clear of $\mathrm{HO}$ and no radiographic reports indicated otherwise. He was advised that a transtibial amputation and use of a prosthesis might allow higher-level activities and possibly minimize pain. The alternative was a ankle fusion, but that would limit his limb function, including higherlevel activities. The patient elected the transtibial amputation and, 4 months later, reported pain in the residual limb caused by a protruding bone. 
A radiograph taken approximately 1 month postamputation was clear, but subsequent radiographs over the next 2 months confirmed evidence of developing HO. This patient was referred for a prosthetic adjustment to resolve the pain associated with the ectopic bone, but this was unsuccessful. The location of the HO was on the anterolateral aspect of the distal tibia, which is a pressure-sensitive area for fitting into the prosthetic socket (Figure 6) [16-17]. The patient's radiograph shows the focused protrusion of excess bone growth, and physical examination indicated it interfered with a comfortable fit.

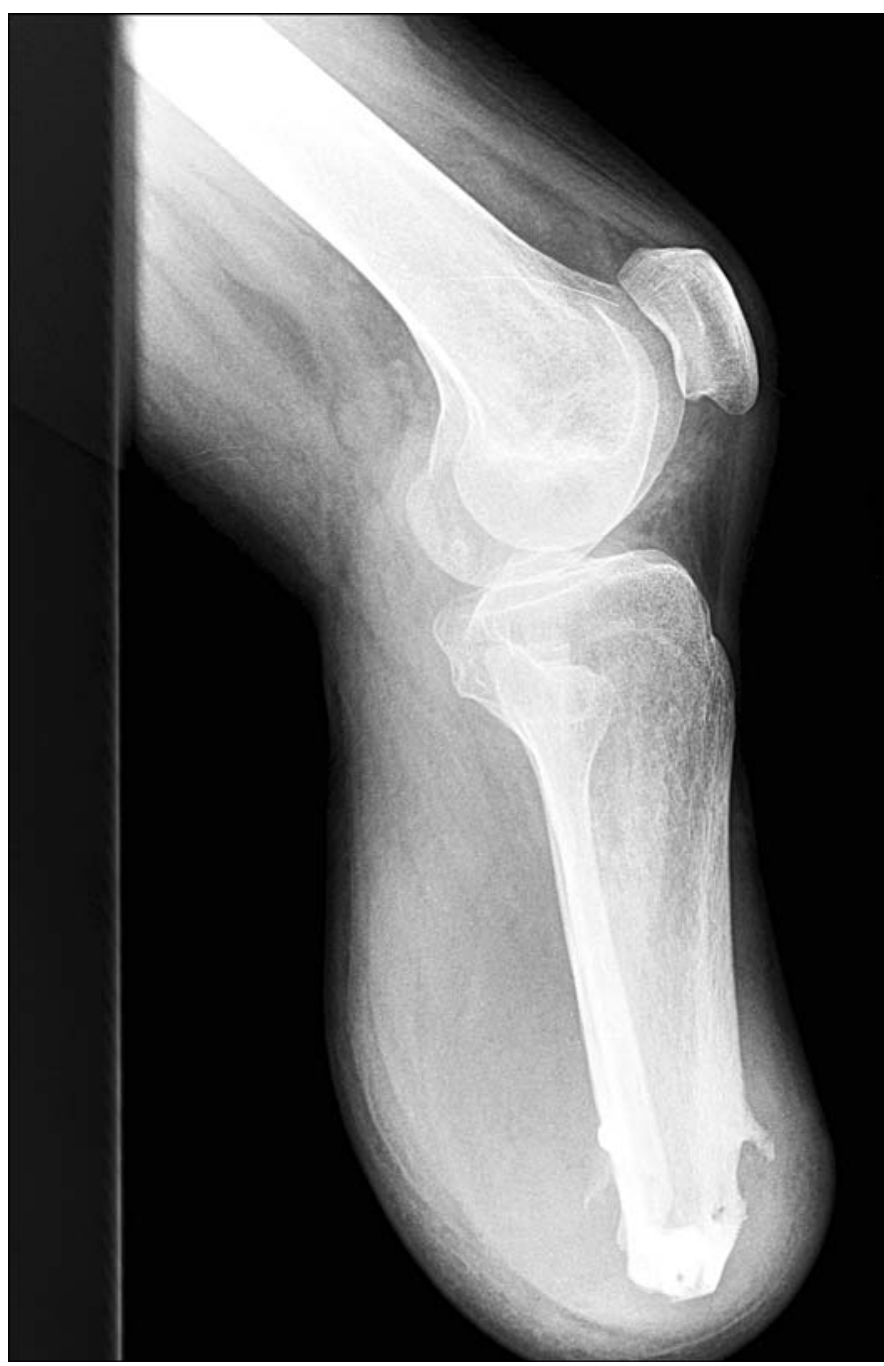

Figure 6.

Radiograph showing protrusion of excess bone growth (heterotopic ossification [HO]) following an elective transtibial amputation in case history 5. Prosthetic adjustments were unsuccessful, and HO required surgical excision to restore function.
Ten months after the transtibial amputation, surgical excision of HO relieved pain and restored function. This patient had radiation therapy to protect against HO following surgery. The patient developed a postsurgical infection, and a 6-week course of antibiotics resolved the infection. The patient presently is functioning well using the prosthesis, with no HO recurrence, and has recovered almost fully from his other limb injuries. The patient's military status is pending.

\section{DISCUSSION}

This article is one of the first to describe individual case histories of $\mathrm{HO}$ among recent U.S. combat amputee patients returning from the Afghanistan and Iraq wars between 2007 and 2008. The present results extend previous clinical observations [1-2] by integrating data from radiographs and patient symptoms to illustrate a number of relevant patient care issues. First, the location of HO relative to the prosthesis can influence whether patients develop symptoms. Radiographs and physical examination may reveal significant, even palpable, HO without symptoms in the residual limb (case 1). One-third of patients (5 of 15) who had radiographic evidence of at least moderate $\mathrm{HO}$ did not report pain or other symptoms from excess bone growth that interfered with prosthetic use. The position of moderate excess bone growth may not affect pressure-sensitive areas of the residual limb and interfere with prosthetic fitting [16-17]. In other cases, focused projections of HO may affect pressure-sensitive areas of the residual limb and cause adverse symptoms requiring prosthetic adjustments and even surgical excision (case 5).

A second, related patient care issue as seen in case history 2 was that $\mathrm{HO}$ might benefit prosthetic fitting in transfemoral amputees. Specifically, when the excess bone growth expands surrounding the distal portion of the amputated bone (Figure 3; also see Figure 5), it can effectively provide an anatomic structure that the prosthetist can use to improve suspension of the prosthesis on the residual limb. The HO prevents the prosthesis from sliding down the residual limb during the swing phase of walking [16]. Follow-up discussion with the prosthetist for this patient series indicated that, while this benefit was not common, ectopic bone had been used to enhance prosthetic fitting in two other transfemoral amputees in the present case series. 
More generally, for the prosthetist, HO represents an additional pressure-sensitive area in the residual limbs of recent combat amputees. In the first 6 months after amputation, providers can expect to complete multiple modifications to accommodate $\mathrm{HO}$ as it typically grows and changes shape within the residual limb. These initial modifications may be transient solutions but are important in the context of ongoing rehabilitation to keep the amputee walking as much as possible. Subsequently, the ectopic bone may stabilize, but long-term changes in combatrelated $\mathrm{HO}$ are largely unknown and providers are advised to track its progress with annual examinations and/or radiographs. Some patients manage some minimal to moderate HO-related pain, at least in the first year or two (e.g., case history 2). Data are needed on longer-term outcomes in the years following amputation and, ultimately, as patients approach middle age. Minimal pain for younger patients may later become more functionally limiting and require further adjustments or treatments.

The treating prosthetist for this case series indicated that HO added significant time (sometimes weeks) and complexity to the typical fitting process, particularly in an effort to avoid surgical excision of HO. In general, practitioners are advised to consider the full range of flexible materials to accommodate HO-related symptoms. These include using silicone, urethane, gels, and thermoplastics, with a goal of loading pressure-tolerant rather than pressure-sensitive areas of the residual limb. Standard processes of grinding, padding, heating, and shaping of materials can be used for optimizing socket fit for patient function and comfort. Notably, the patient's perceived point of pain may not directly correlate with the actual anatomical location of pain.

A third patient care issue illustrated in several cases was the risks and benefits to consider in surgical treatment of symptoms of patients for whom HO caused pain and interfered with prosthetic fitting and walking. Recent combat amputees are relatively young, fit, and motivated to pursue higher-level activities using prosthetics, such as running and sports [5,9]. Nonetheless, the surgical and rehabilitation teams for this case series emphasized nonsurgical management consisting of multiple attempts to minimize symptoms through prosthetic adjustments and/ or pain management techniques. Surgical excision was considered a final option and weighed against the additional risks of surgical infection or other complications. A review of 25 residual limbs of combat amputees that had excision found $\mathrm{HO}$ recurrence in only 2 of the 25 cases (both asymptomatic) between 6 and 24 months later. Twenty of these limbs received postsurgical radiation as prophylaxis [1]. Follow-up surgeries to excise HO may lead to more complicated reconstructive procedures and increased risk of complications such as infections. Recent studies indicate a trend down the "reconstructive ladder" favoring the use of split thickness skin grafts rather than more complicated free flaps [18-19]. Notably, HO can cause recurrent skin breakdown and infection associated with skin grafts (e.g., case history 4). For transfemoral amputees in particular, surgical excision of the ectopic bone may result in inadequate residual soft tissue in residual limbs near joints and risk level loss or the need for more complicated procedures such as a free flap. Any reduction in limb length may substantially increase patients' energy expenditure while walking [20-23].

A fourth issue seen in several case histories was the use of nonsteroidal anti-inflammatory medications (e.g., Celebrex, indomethacin) or the bisphosphonate etidronate shortly after injury as prophylaxis against initial development of HO. These medications did not appear effective in the present case histories, although they may have inhibited further development of HO. Nonsteroidal anti-inflammatory agents and radiation are known to be effective prophylaxis against HO following hip surgery in civilians [24]. A program description of the Walter Reed Amputee Patient Care Program indicates physicians prescribed nonsteroidal anti-inflammatory drugs such as Celebrex for combat amputees, unless contraindicated, for both prophylaxis and treatment of HO [25]. This issue has been reviewed previously [2]. Briefly, nonsteroidal anti-inflammatory agents (e.g., Celebrex) can inhibit excess bone growth and therefore are contraindicated for patients with fractures because these medications can inhibit the healing of long bone fractures. Afghanistan and Iraq war combat amputees often sustain substantial injuries other than amputation including fractures and soft-tissue damage [5,9]. Celebrex in particular is not known to interfere with blood platelets or clotting to increase bleeding like other nonsteroidal antiinflammatory agents. Etidronate is a bisphosphonate that has been used for preventing HO following hip surgery, TBI, and spinal injury [26-27]. Etidronate can inhibit new bone development and may be prescribed for a number of months, along with anti-inflammatory agents. However, a recent review suggests more study is needed to evaluate its effectiveness for trauma patients [26]. Etidronate may act by delaying rather than preventing $\mathrm{HO}$, which may recur following cessation of this medication. 
As discussed previously, risk factors such as amputations within the zone of blast injury [1] and higher injury severity scores [3] may allow candidate patients for prophylactic medication to be identified according to the specific risks and benefits of each case. Unfortunately, no systematic research exists to support the effectiveness or ineffectiveness of nonsteroidal anti-inflammatory agents or other medications as prophylaxis for $\mathrm{HO}$ in combat amputees [27]. Current research has focused on identifying early postinjury sera, wound, or injured-tissue biomarkers, as well as genetic profiles that might identify those among battle injury patients at risk for HO [4]. Successfully integrating an individual's genetic predispositions and specific wound biomarkers appears to be the most comprehensive strategy for early intervention with HO prophylactic treatments.

The present study did not include data on soft-tissue treatment because this factor has been evaluated $[1,3]$. Two studies found increased soft-tissue treatments among amputees who developed HO but concluded that the effects were not substantial clinically. Forsberg et al. found that injury severity, but not soft-tissue treatment procedures, was an independent predictor of HO in multivariate analysis [3]. They concluded that increased injury severity was the relevant predictor of ectopic bone development and that increased soft-tissue treatments were byproducts of high injury severity of the associated wounds.

Finally, heterotopic ossification apparently can occur in patients who elect to have amputations performed many months after combat injury. Two cases (3 and 5) were presented in which patients showed no radiographic evidence of ectopic bone growth until after elective amputation. The excess bone growth was not as substantial radiographically as the remaining cases of combat-related HO. However, it was unfortunately positioned in the residual limb relative to the prosthesis and therefore caused the patient pain during ambulation. Surgical excision was required in both cases to restore a comfortable prosthetic fit. Smith noted similar bone growth occasionally might occur following traumarelated amputations or when residual periosteum forms irregular bone spurs [28]. Whether recent combat amputees might have increased risk of this phenomenon is unclear. As mentioned, HO occurred in three of the eight patients who had delayed amputations in the present case series.

The present study was limited by its small sample size. Therefore, any conclusions about the possible relationship between symptomatic $\mathrm{HO}$ and its location in the residual limb will require additional investigation in larger samples in a prospective study. However, a number of findings of the present study were similar to those reported in a previous large sample study [1]. First, blasts were the predominant mechanism of injury. Second, approximately 60 percent of residual limbs showed radiographic evidence of $\mathrm{HO}$ in the present study and previous large sample study. Third, surgical excision was uncommon in the present study (4 of 33 limbs) and past study (7\%) [1]. Finally, approximately one-third of limbs in the present sample had symptomatic HO. The previous research did not detail symptoms such as prosthetic adjustments but reported that one-third of residual limbs had moderate or severe radiographic HO [1].

The case histories selected for the present study intentionally focused on patients who had at least some evidence of radiographic HO. We recognize that a substantial percentage of recent Afghanistan and Iraq war combat amputees do not show radiographic $\mathrm{HO}$ and advise the reader that surgical excision is uncommon [1]. However, the purpose of these case histories was to illustrate variability in symptoms and possible causes of symptoms among patients who did show radiographic HO. The true rates of the selected cases are unclear. Some cases may be uncommon but do not appear rare, such as moderate $\mathrm{HO}$ without symptoms (5 of 15 limbs in the present study including case 1) and ectopic bone growth requiring excision following delayed amputations ( 2 of 8 patients with delayed amputations, including cases 3 and 5).

\section{CONCLUSIONS}

The present study described radiographic and symptomatic evidence of $\mathrm{HO}$ for a small patient series of recent Afghanistan and Iraq war combat amputees (between 2007 and 2008). Approximately one-third of patients who showed at least moderate HO in their radiographs did not report adverse symptoms. Five patient case histories presented described a range of relevant clinical care issues, such as the location of $\mathrm{HO}$ relative to the prosthesis and potential benefits for prosthetic suspension, use of prophylactic medication, prosthetic adjustments, risks and benefits of surgical excision, and $\mathrm{HO}$ following delayed amputations. Case histories illustrated how the location of the HO development relative to pressure-sensitive and pressure-tolerant areas of the residual limb may determine whether patients experienced symptoms that interfered with prosthetic use and walking. 


\section{ACKNOWLEDGMENTS}

\section{Author Contributions:}

Study concept and design: T. Melcer, B. Belnap, P. Konoske, G. J. Walker, M. Galarneau.

Acquisition of data: T. Melcer, B. Belnap, P. Konoske, G. J. Walker, M. Galarneau.

Analysis and interpretation of data: T. Melcer, B. Belnap, P. Konoske, G. J. Walker, M. Galarneau.

Drafting of manuscript: T. Melcer, B. Belnap, P. Konoske, G. J. Walker. Critical revision of manuscript for important intellectual content: T. Melcer, B. Belnap, P. Konoske, G. J. Walker, M. Galarneau. Statistical analysis: T. Melcer, G. J. Walker.

Obtained funding: M. Galarneau.

Administrative, technical, or material support: T. Melcer,

G. J. Walker, B. Belnap, M. Galarneau.

Study supervision: T. Melcer.

Financial Disclosures: The authors have declared that no competing interests exist.

Funding/Support: This material is the result of work supported with resources of the Office of Naval Research, Arlington, Virginia, under work unit No. 60332.

Additional Contributions: We gratefully acknowledge Judy Dye, NP; Martin Lebedda, RN; and Patricia Stout, RN, for their clinical support in reviewing patient records and CPT Jay Pyo, DO, MC, USA, and Peter Harsch, CP, for their comments on the manuscript. The views expressed in this article are those of the authors and do not necessarily reflect the official policy or position of the Department of the Navy, Department of Defense, or the U.S. Government. The article is approved for public release; distribution is unlimited.

Institutional Review: An institutional review board approved the study protocol. Of the patients who were recruited, more than 90 percent participated in the study after giving their free and informed written consent. This research has been conducted in compliance with all applicable Federal regulations governing the protection of human subjects in research (protocol NHRC.2007.0016).

Participant Follow-Up: The authors plan to inform participants of the publication of this study. However, we may not reach all participants because their contact information may have changed.

\section{REFERENCES}

1. Potter BK, Burns TC, Lacap AP, Granville RR, Gajewski DA. Heterotopic ossification following traumatic and combat-related amputations. Prevalence, risk factors, and preliminary results of excision. J Bone Joint Surg Am. 2007; 89(3):476-86. [PMID: 17332095]

DOI:10.2106/JBJS.F.00412

2. Potter BK, Burns TC, Lacap AP, Granville RR, Gajewski DA. Heterotopic ossification in the residual limbs of traumatic and combat-related amputees. J Am Acad Orthop Surg. 2006;14(10 Spec No.):S191-97. [PMID: 17003198]

3. Forsberg JA, Pepek JM, Wagner S, Wilson K, Flint J, Andersen RC, Tadaki D, Gage FA, Stojadinovic A, Elster EA. Het- erotopic ossification and high-energy wartime extremity injuries: Prevalence and risk factors. J Bone Joint Surg Am. 2009;91(5):1084-91. [PMID: 19411456]

DOI:10.2106/JBJS.H.00792

4. Forsberg JA, Potter BK. Heterotopic ossification in wartime wounds. J Surg Orthop Adv. 2010;19(1):54-61.

[PMID: 20371008]

5. Potter BK, Scoville CR. Amputation is not isolated: An overview of the U.S. Army Amputee Patient Care Program and associated amputee injuries. J Am Acad Orthop Surg. 2006;14(10 Spec No.):S188-90. [PMID: 17003197]

6. König TC, Lawton G, Osborne I, Patel H, Ang S. Heterotopic ossification and traumatic limb amputation after terrorist bomb blast: A series of cases from the London bombings of 7 July 2005. J R Army Med Corps. 2007;153(2):133.

7. Warmoth JE, Reigel B, McFall TL, Pugh G, Alvarez L, Melton DM, Shelton AD. Heterotopic ossification associated with traumatic amputation. J Prosthet Orthot. 1997;9(1):33-37.

8. Dudek NL, DeHaan MN, Marks MB. Bone overgrowth of the adult traumatic amputee. Am J Phys Med Rehabil. 2003;82(11):897-900. [PMID: 14566159] DOI:10.1097/01.PHM.0000087459.94599.2D

9. Pasquina PF, Bryant PR, Huang ME, Roberts TL, Nelson VS, Flood KM. Advances in amputee care. Arch Phys Med Rehabil. 2006;87(3 Suppl 1):S34-S45. [PMID: 16500191] DOI:10.1016/j.apmr.2005.11.026

10. Melcer T, Walker GJ, Galarneau M, Belnap B, Konoske P. Midterm health and personnel outcomes in recent combat amputees. Mil Med. 2010;175(3):147-54. [PMID: 20358702]

11. Covey DC, Aaron RK, Born CT, Calhoun JH, Einhorn TA, Hayda RA, Levin LS, Mazurek MT, Murray CK, Powell ET, Schwarz EM, Wenke JC. Orthopaedic war injuries: From combat casualty care to definitive treatment: A current review of clinical advances, basic science, and research opportunities. Instr Course Lect. 2008;57:65-86. [PMID: 18399571]

12. Andersen RC, Frisch HM, Farber GL, Hayda RA. Definitive treatment of combat casualties at military medical centers. J Am Acad Orthop Surg. 2006;14(10 Spec No.):S24-31. [PMID: 17003202]

13. Jefferies VN. Heterotopic ossification, U.S. Armed Forces, 2002-2007. Med Surveill Mon Rep. 2007;14(5):7-9.

14. Copes WS, Champion HR, Sacco WJ, Lawnick MM, Keast SL, Bain LW. The Injury Severity Score revisited. J Trauma. 1988;28(1):69-77. [PMID: 3123707] DOI:10.1097/00005373-198801000-00010

15. Galarneau MR, Hancock WC, Konoske P, Melcer T, Vickers RR, Walker GJ, Zouris JM. The Navy-Marine Corps Combat Trauma Registry. Mil Med. 2006;171(8):691-97. [PMID: 16933807]

16. Michael JW. Prosthetic suspensions and components. In: Smith DG, Michael JW, Bowker JH, editors. Atlas of amputations and limb deficiencies: Surgical, prosthetic, and 
rehabilitation principles. 3rd ed. Rosemont (IL): American Academy of Orthopedic Surgeons; 2004. p. 409-28.

17. Braddom RL. Physical medicine and rehabilitation. Philadelphia (PA): Saunders Elsevier; 1996.

18. Parrett BM, Matros E, Pribaz JJ, Orgill DP. Lower extremity trauma: Trends in the management of soft-tissue reconstruction of open tibia-fibula fractures. Plast Reconstr Surg. 2006; 117(4):1315-24. [PMID: 16582806] DOI:10.1097/01.prs.0000204959.18136.36

19. Ullmann Y, Fodor L, Ramon Y, Soudry M, Lerner A. The revised "reconstructive ladder" and its applications for high-energy injuries to the extremities. Ann Plast Surg. 2006;56(4):401-5. [PMID: 16557072]

DOI:10.1097/01.sap.0000201552.81612.68

20. Kapp SL, Fergason JR. Transtibial amputation: Prosthetic management. In: Smith DG, Michael JW, Bowker JH, editors. Atlas of amputations and limb deficiencies: Surgical, prosthetic, and rehabilitation principles. 3rd ed. Rosemont (IL): American Academy of Orthopedic Surgeons; 2004. p. 503-16.

21. Baum BS, Schnall BL, Tis JE, Lipton JS. Correlation of residual limb length and gait parameters in amputees. Injury. 2008;39(7):728-33. [PMID: 18541239] DOI:10.1016/j.injury.2007.11.021

22. Schnall BL, Baum BS, Andrews AM. Gait characteristics of a soldier with a traumatic hip disarticulation. Phys Ther. 2008;88(12):1568-77. [PMID: 18849481]

23. Hosalkar H, Hsu J, Pandya NK, Keenan MA. What's new in orthopaedic rehabilitation. J Bone Joint Surg Am. 2008; 90(10):2301-11. [PMID: 18829929]

DOI:10.2106/JBJS.H.00943

24. Vavken P, Castellani L, Sculco TP. Prophylaxis of heterotopic ossification of the hip: Systematic review and metaanalysis. Clin Orthop Relat Res. 2009;467(12):3283-89.
[PMID: 19517202]

DOI:10.1007/s11999-009-0924-5

25. Pasquina PF. Optimizing care for combat amputees: Experiences at Walter Reed Army Medical Center. J Rehabil Res Dev. 2004;41(3A):vii-xii. [PMID: 15543454] DOI:10.1682/JRRD.2004.05.0051

26. Haran M, Bhuta T, Lee B. Pharmacological interventions for treating acute heterotopic ossification. Cochrane Database Syst Rev. 2004;4:CD003321. [PMID: 15495048]

27. Cullen N, Perera J. Heterotopic ossification: Pharmacologic options. J Head Trauma Rehabil. 2009;24(1):69-71.

[PMID: 19158599$]$

DOI:10.1097/HTR.0b013e31819a8fcc

28. Smith DG. General principles of amputation surgery. In: Smith DG, Michael JW, Bowker JH, editors. Atlas of amputations and limb deficiencies: Surgical, prosthetic, and rehabilitation principles. 3rd ed. Rosemont (IL): American Academy of Orthopedic Surgeons; 2004.

Submitted for publication March 10, 2010. Accepted in revised form July 20, 2010.

This article and any supplementary material should be cited as follows:

Melcer T, Belnap B, Walker GJ, Konoske P, Galarneau M. Heterotopic ossification in combat amputees from Afghanistan and Iraq wars: Five case histories and results from a small series of patients. J Rehabil Res Dev. 2011; 48(1):1-12.

DOI:10.1682/JRRD.2010.03.0033

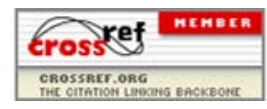


